\title{
Comparative study of sour cherry samples for their anthocyanin content measured by tools of the laboratory and by portable equipments
}

\author{
Szemán-Nagy, G. ${ }^{1}$, Pintér, G. ${ }^{1}$, Prokisch, J. ${ }^{2}$, Tornyai, J. ${ }^{3}$, Nyéki, J. ${ }^{3}$, Szabó, Z. ${ }^{4}$, Szabó, T. ${ }^{5}$ \& Fári, M.G. ${ }^{6}$ \\ ${ }^{1}$ University of Debrecen, Faculty of Science and Technology, \\ Microbiocal Biotechnology and Cell Biology Department, \\ ${ }^{2}$ University of Debrecen, Molecular Nano-Biological Institute, \\ ${ }^{3}$ University of Debrecen, Institute for Research and Development \\ ${ }^{4}$ University of Debrecen, Institute of Horticulture \\ ${ }^{5}$ Fruit Research and Extension Institute Centre of Újfehértó \\ ${ }^{6}$ University of Debrecen, Depratment of Plant Biotechnolgy (e-mail: fari@agr.unideb.hu)
}

\begin{abstract}
Summary: The inner quality of fruits depends on many components. The analysis of pharmacologically important fruit species as the sour cherry consumed as a common food is an expensive task, mostly requiring an equipped laboratory. In sour cherry, one of its valuable components, the anthocyanin content deserves special attention. A portable analytical implement, which has been developed by our team measures the anthocyanin content on a scale of 1024 PharM grades. The system is a member of the UVEX family of implements working with a microprocessor and performs the measurement quickly. The portable variant (UVEX-ML-1) does not require much training, the laboratory variant (UVEX UL-1) performs a large quantity of tests under modest laboratory conditions. Preparation of the samples is easily done, the necessary elements are available in the trade. The reagent is easily stored and dosed. The system was tested and proved to be of sufficient precision and the result showed acceptable variance according to the checks performed by a spectrophotometer in the laboratory.
\end{abstract}

Key words: Hungarian sour cherry varieties, farma-sour cherry, Bioactive substances, analytical implements

\section{Introduction}

Evidence suggests that a diet high in fruits and vegetables may decrease the risk of chronic diseases such as cardiovascular disease and cancer, and phytochemicals, including phenolics, flavonoids and carotenoids from fruits and vegetables may play a key role in reducing risk of chronic diseases. Recent research has proved that sour cherry (Prunus cerasus L.) is valuable natural source of some bioactive compounds important in human health preservation, like anthocyanines. Wang et al. (1999) in their study related 17 antioxydant compounds available in the sour cherry and their role in preserving human health, concerning the achievements of which ten USA- patents have been granted since 1999. The studies covered the varieties "Montmorency" and "Balaton". The latter is of Hungarian origin, we call it "Újfehértói fürtös". In the mentioned varieties, high anthocyanine, Bioflavonoid, melatonine and other bioactive components were measured, which have antiflammatory and cancer-preventive effects.

The anthocyanin content of sour cherry varies according to varieties, growing sites, moreover growing seasons and environmental conditions, dynamically. In our earlier work, we identified the total antioxidant activity, anthocyanin content and "antioxydant density" of sour cherry varieties, "Újfehértói für- tös", "Debreceni bőtermő", "Kántorjánosi" and "Érdi bőtermő" and some "Bosnyák" sour cherry clones (Veres et al., 2005).

The few measurements in the laboratory of high precision could be completed with tracing the timely changes and compared them. The high concentration of the dyes, however, limited the use of paper streaks if precise tests are expected.

For the purpose to use portable implements, we developed diagnostical kits with the necessary supplements. We aimed to use this construction as an internationally new tool for measuring samples either of fresh fruit or frozen samples and serve the work of growers as well as processors and researchers.

\section{Materials and methods}

\section{Functioning of the implement}

The portable tools: UVEX ML-1 and UVEX LB-1 (Figures 1 and 2) in the centre is the detector is a bore-hole of $12.6 \mathrm{~mm}$ for the vial with the liquid to be measured. The vial in illuminated by a LED on one side and a photo-detector is on the other side. The absorption of the sample is calculated by the difference between the intensities of LED and the reduced intensity arriving into the detector. The emitted 
intensity of the LED is regulated by the software. The temperature dependence of the light-permeability is also considered by the software. The data are transferred and stored in a central processor: EEPROM. A built in signaliser, LCD, and a keyboard facilitates the intervention of the user, and the connection with a PC using Windows software is possible.

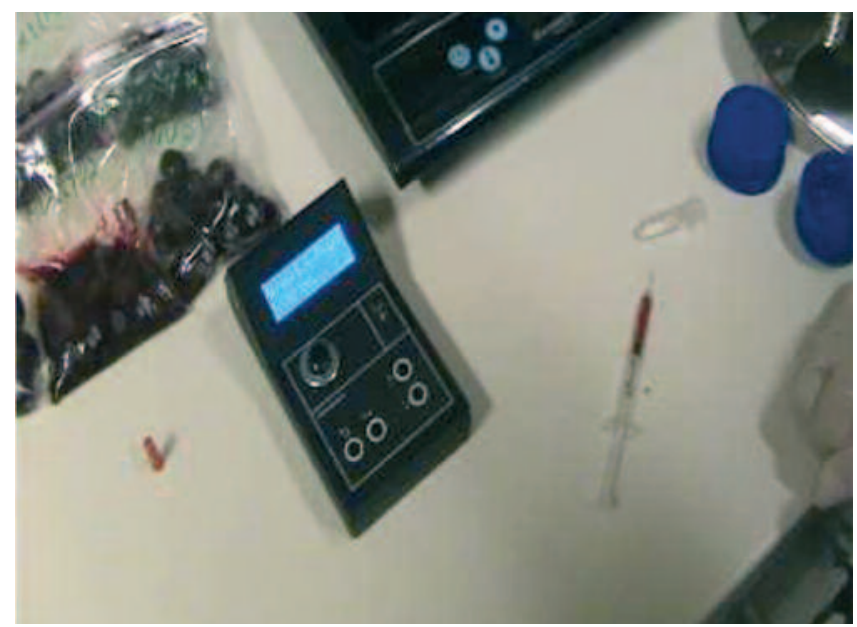

Figure 1. UVEX ML-1, the portable implement and its supplement for the quick measurement of the anthocyanin content of sour cherry fruits

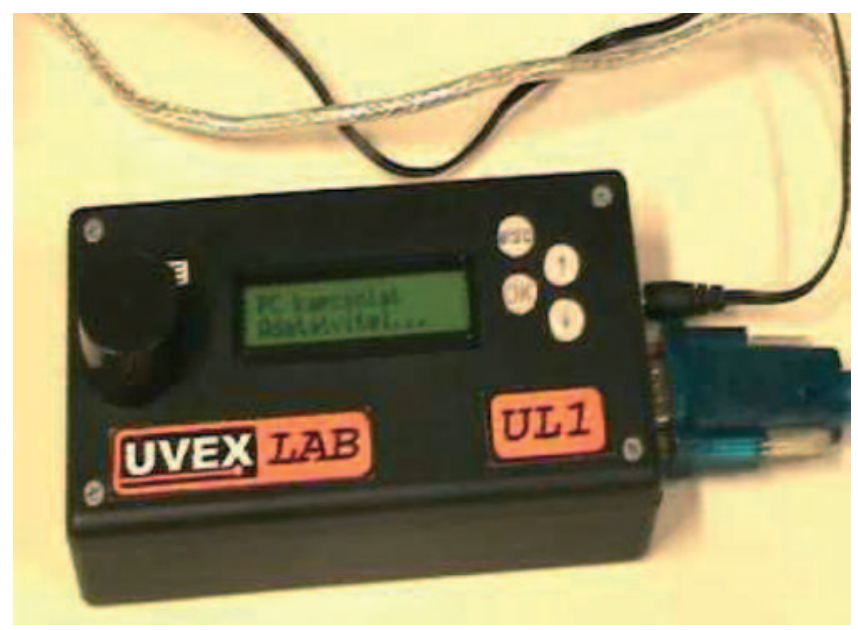

Figure 2. UVEX UL-1, the portable laboratory implement for the quick measurement of the anthocyanin content of sour cherry fruits

\section{Illumination}

For the reagent used, the LED is emitting $532 \mathrm{~nm}$ (green) light, and is regulated by PWM-generator. The LED is glittering at high frequency, but the photo-resistance will iltered out the sign of high frequency.

\section{Light-measuring}

The tension of the photo-resistance is produced by a generator of $250 \mu \mathrm{A}$ performance. The generator is equipped by a resistance of $1 \%$ tolerance and by two amplifiers. Thus the measurement is adjusted to the desirable tension. Because the weak currant, the warming up is negligible. The tension exerted on the resistance is measured by a fourth-degree integrating filter and the central processor using an analog/digital transformer of 10 bites. The filter is calibrated to withstand troubles above $50 \mathrm{~Hz}$. The software commands the average of 16 measurements, which eliminates smaller $(<50 \mathrm{~Hz})$ troubles.

\section{Measurement of temperature}

The light-sensor is temperature dependent, therefore the environment is measured by a TC77 temperature sensor. The sensor induces an adequate tension, which is processed by the Analog/Digital transformer of 10 bites capacity. The offset error is subtracted from the measuring tension by the processor.

\section{The handling surface}

The handling surface is accessible by a system of menus of several levels. The system of menus is signalised by two rows LCD. The navigation is performed on the lower part of the tool by up/down and OK/back buttons. The menu system is Hungarian with accented letters.

\section{The central processor}

The function of a central processor is assigned to a PIC16F876A type microcontroller. It has a built in programmemory, which accepts programs written in assembly language. The watch-sign of 20Mhz performs algorithms of high velocity, and it disposes of row ports, which transfers immediately the electric scintillation into the PC ports.

\section{Reagents used for the determination of antioxidant content of sour cherries}

The essence of the method is that the anthocyanins are hydrolysed in basic medium and the skeleton anthocyanidin is deprived of protons. The process changes the colour, which is measured at the wavelength of maximal absorption. The reagent contains $0.1 \mathrm{M} \mathrm{NaOH}$ and $0.1 \mathrm{M} \mathrm{Na}_{2} \mathrm{HPO}_{4}$.

\section{The unit PharM}

The PharM unit is a quantitative measure of anthocyanin content in fruits as a source of anthocyanin. This is a pharmacologically relevant measure of determining the value of fruit. With the PharM reagent we are able to evaluate samples. The absorption of light with wavelength $532 \mathrm{~nm}$ is related with the anthocyanin content. The spectrum of transmittance has a scale of 1024 grades. The portable implement stores the data at $1 / 10$ accuracy, but at $1 / 100$ for further processing

\section{Results}

\section{The proceeding of measurement}

The sample of 15-20 fruits is closed in a 200ml (plastic) bag and squeezed manually. The juice is sucked in a $1 \mathrm{ml}$ 
(insulin) syringe through a filter. The liquid is set on $0.5 \mathrm{ml}$ and air is eliminated. Next distilled water is sucked forming $50 \%$ dilution. Homogenised by shaking the syringe. Then 0.5 $\mathrm{ml}$ is filled into the vial containing the reagent, put the cap, shake to mix. After one minute having inserted the vial in the implement, the result is read on the LDC screen. The result is stored in the temporary memory and by pressing a button the data are forwarded into the flash memory of a 100 data capacity, where the last 10 results are immediately available. Under conditions of a laboratory, the last 100 data may appear on the connected PC-screen. The 100 data are available for preparing graphs and tables to statistical softwares. If unexpected high anthocyanin contents appear, a higher dilution may adjust the samples to be measured, and the result ought to be multiplied corresponding with the dilution.

Table 1. The measurement of anthocyanin content in 6 randomly selected sour cherry varieties by spectrophotometer (ABS), by Uvex LB-1 and Uvex ML-1 (Újfehértó, 2009)

\begin{tabular}{|c|c|c|c|}
\hline & ABS at 540nm & UVEX UL-1 & ML-01 at 50\% \\
\hline 1 & 1.231 & 9.13 & 4.71 \\
\hline 2 & 0.665 & 6.72 & 2.8 \\
\hline 3 & 0.601 & 6.45 & 2.7 \\
\hline 4 & 0.371 & 5.05 & 2.22 \\
\hline 5 & 0.514 & 6.23 & 2.5 \\
\hline 6 & 0.353 & 5.46 & 2.15 \\
\hline
\end{tabular}

Table 2. The measurement of anthocyanin content in 6 randomly selected sour cherry varieties with five replications by portable UVEX ML-1 (Újfehértó, 2009)

\begin{tabular}{|l|c|c|c|c|c|}
\hline Samples & $\mathbf{1}$ & $\mathbf{2}$ & $\mathbf{3}$ & $\mathbf{4}$ & $\mathbf{5}$ \\
\hline 1 & 4.86 & 4.66 & 5.25 & 6.72 & 5.23 \\
\hline 2 & 4.95 & 4.67 & 5.36 & 6.79 & 5.29 \\
\hline 3 & 4.85 & 4.71 & 5.27 & 6.56 & 5.23 \\
\hline 4 & 4.79 & 4.7 & 5.29 & 6.47 & 5.27 \\
\hline 5 & 4.79 & 4.71 & 5.32 & 6.42 & 5.19 \\
\hline 6 & 4.86 & 4.76 & 5.28 & 6.72 & 5.26 \\
\hline Variance (StDev) & 0.06 & 0.04 & 0.04 & 0.15 & 0.04 \\
\hline Mean & 4.9 & 4.7 & 5.3 & 6.6 & 5.2 \\
\hline
\end{tabular}

Table 3. Measurement of 19 experimental sour cherry varieties and clones by UVEX-ML-1 portable implement on diluted samples (Újfehértó, 2009)

\begin{tabular}{|c|l|c|c|l|c|}
\hline $\begin{array}{l}\text { Num- } \\
\text { ber }\end{array}$ & Variety/clone & $\begin{array}{c}\text { PharM- } \\
\text { value }\end{array}$ & Number & Variety/clone & $\begin{array}{c}\text { PharM- } \\
\text { value }\end{array}$ \\
\hline 1. & D-klón & 4.2 & 11. & N-2 & 9 \\
\hline 2. & Kántorjánosi & 4.2 & 12. & L & 9.6 \\
\hline 3. & Debreceni bötermö & 4.4 & 13. & M & 9.8 \\
\hline 4. & Pándy 279 & 4.6 & 14. & A & 10.6 \\
\hline 5. & Petri & 4.7 & 15. & Oblacsinszka & 16.4 \\
\hline 6. & Éva (T) & 5.1 & 16. & VN-07 & 18.4 \\
\hline 7. & Érdi bőtermő & 5.7 & 17. & VN-04 & 20.4 \\
\hline 8. & Pipacs 1 & 6.2 & 18. & Csengődi & 21.6 \\
\hline 9. & Újfehértói fürtös & 7.1 & 19. & VN-01 & 39.6 \\
\hline 10. & E & 8.4 & & & \\
\hline
\end{tabular}

\section{Testing of the system}

The portable UVEX ML-1 implement (Figure 1) was checked with six samples, which were repeatedly measured also with ABS spectrophotometry. Measurement in the laboratory were somewhat more precise, but the variance of the result was better than sufficient. We stated that the portable instrument could be accepted also with 50\% sensibility (Table 1). The getting out of tune in the detector of the instrument was checked five times with measuring the same 6 samples. 30 measurements were made in a quick sequence with less than 2 minutes intervals. The result was reassuring on the basis of a series of attempts (Table 2).

\section{Field measurements}

In 2009, 19 sour cherry varieties and clones were measured for anthocyanin content with the UVEX ML-1, and the PharM values were read in double diluted samples because there were also "farma-meggy" (high anthocyanin content) clones (Veres et al., 2005), i.e. numbers 15-19 (Table 3).

\section{Conclusion}

Two implements have been developed for the purpose of using in the laboratory and in the field, a portable variant (Uvex LB-1 and Uvex ML-1), which facilitate the determination anthocyanin content sour cherry fruits in the field or in the anywhere in the shops, transports and in the processing plants.

The instruments are the first produced for practical purposes, and they may find application for other fruits as conditions of a cheap and quick method.

The research is continued in the University Debrecen AGTC Department of Plant Biotechnology, Laboratory of "Orsós Ottó" and commissioned by the Biotechnology Foundation "Ereky Károly".

\section{Acknowledgement}

The research has been supported by the "New Hungary Development Project" No. GOP- 1.3.1.-08/2-2009-007 and by the National Research and Technology Bureau (NKTH), project No. EA-2044-010/2009 and Ereky Foundation, Hungary.

\section{References}

Wang, H., Nair, M. G., Stasburg, G. M., Booren, A. M. \& Gray, J. I. (1999): Antioxidant polyphenols from tart cherries (Prunus cerasus). J. Agric. Food Chem. 47: 840-844.

Veres, Zs., Holb, I., Nyéki, J., Szabó, Z. \& Fári, M.G. (2005): Total anthocyanine content and antioxidant density of some Hungarian sour cherry varieties. Inter. J. Hortic. Sci. 11 (2): 109-111. 